\title{
Micellar high performance liquid chromatographic determination of Itraconazole in bulk, pharmaceutical dosage forms and human plasma
}

\author{
Mohamed Rizk, Safaa Shafik Toubar, Maha Mahmoud Abou El-Alamin*, \\ and Marwa Mohamed Mahmoud Azab \\ Analytical Chemistry Department, Faculty of Pharmacy, Helwan University, 11795, Cairo, Egypt \\ ${ }^{*}$ Corresponding author at: Analytical Chemistry Department, Faculty of Pharmacy, Helwan University, 11795, Cairo, Egypt. \\ Tel.: +2.02.25541601. Fax:+2.02.25541601. E-mail address: dr.maha.alamin@gmail.com (M.M.A. El-Alamin).
}

\section{ARTICLE INFORMATION}

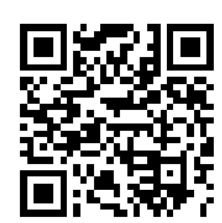

DOI: 10.5155/eurjchem.5.1.11-17.885

Received: 25 July 2013

Received in revised form: 13 August 2013

Accepted: 13 August 2013

Online: 31 March 2014

\section{KEYWORDS}

\section{Stability}

Itraconazole

Anti-fungal drugs

Method validation

Micellar liquid chromatography

Optimization and system suitability

\section{Introduction}

Itraconazole (ITC), is a triazole compound, chemically described as $(2 R, 4 S)$-rel-1-(butan-2-yl)-4-\{4-[4-(4-\{[(2R,4S)-2(2,4-dichlorophenyl)-2-(1H-1,2,4-triazol-1-ylmethyl)-1,3-dioxo lan-4-yl]methoxy\}phenyl)piperazin-1-yl]phenyl\}-4,5-dihydro1H-1,2,4-triazol-5-one (Figure 1). It is an orally active antifungal drug and extensively metabolized in the liver by the cytochrome P450 isoenzymes. ITC inhibits fungi ergosterol synthesis. Depletion of ergosterol in fungal membrane disrupts the structure and many functions of fungal membrane leading to inhibition of fungal growth [1].

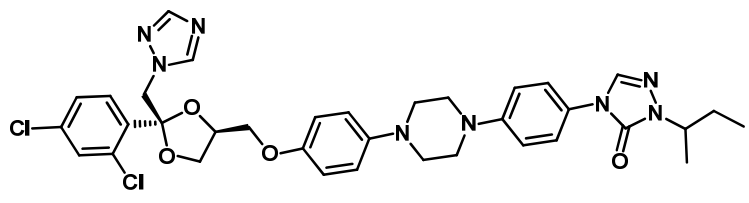

Figure 1. Chemical structure of ITC.

ITC bulk drug is official in British pharmacopeia [2] and in European pharmacopeia [3] and assayed using non-aqueous titration.
Many methods for analysis of the cited compound have been reported, e.g. high pressure liquid chromatography (HPLC) [4-12], liquid chromatography-mass spectrometry (LCMS-MS) [13-16], electrokinetic chromatography [17], micellar electrokinetic chromatography [18], capillary electrophoresis $[19,20]$ and spectrophotometric methods $[21,22]$. In reverse phase high-performance liquid chromatography (RP-HPLC), each component interacts with the stationary phase in a different manner depending upon its polarity and hydrophobicity. Thus, a separation of components is achieved based on polarity. The addition of micelles to the mobile phase introduces a third phase into which the solutes may partition.

Micellar liquid chromatography (MLC) is a form of reversed phase liquid chromatography that uses an aqueous micellar solutions as the mobile phase. The use of micelles in high performance liquid chromatography was first introduced by Armstrong and Henry in 1980 [23]. The technique is used mainly to enhance retention and selectivity of various solutes that would otherwise be inseparable or poorly resolved. Micelles are composed of surfactant, or detergent, monomers with a hydrophobic moiety, or tail, on one end, and a hydrophilic moiety, or head group, on the other. The polar head group may be anionic, cationic, zwitterionic, or non-ionic. The most commonly used surfactant in MLC is the anionic sodium dodecyl sulphate (SDS). When the concentration of a surfactant 
in solution reaches its critical micelle concentration (CMC), it forms micelles which are aggregates of the monomers. The CMC is different for each surfactant, as is the number of monomers which make up the micelle, termed the aggregation number (AN). In MLC, there are three partition coefficients which must be taken into account. The solute will partition between the water and the stationary phase, the water and the micelles, and the micelles and the stationary phase, so gives a large versatility to this technique and make it appropriate for a wide range of solutes that can be separated in one run.

Many of the characteristics of micelles differ from those of bulk solvents. For example, the micelles are, by nature, spatially heterogeneous with a hydrocarbon, nearly anhydrous core and a highly solvated, polar head group. They have a high surfaceto-volume ratio due to their small size and generally spherical shape. Their surrounding environment $(\mathrm{pH}$, ionic strength, buffer ion, presence of a co-solvent, and temperature) has an influence on their size, shape, critical micelle concentration, aggregation number and other properties.

The main limitation in the use of MLC is the reduction in efficiency (peak broadening) that is observed when purely aqueous micellar mobile phases are used [24]. Several explanations for the poor efficiency have been theorized. Poor wetting of the stationary phase by the micellar aqueous mobile phase, slow mass transfer between the micelles and the stationary phase, and poor mass transfer within the stationary phase have all been postulated as possible causes. To enhance efficiency, the most common approaches have been the addition of small amounts of organic modifiers, particularly alcohol, and increasing the column temperature. Care needs to be taken when determining how much organic to add. Too high a concentration of the organic may cause the micelle to disperse, but a generally accepted practice is to keep the volume percentage of organic below $15-20 \%$.

Despite the reduced efficiency verses RP-HPLC, hundreds of applications have been reported using MLC. One of the most advantageous is the ability to directly inject physiological fluids. Micelles have an ability to solubilize proteins which enables MLC to be useful in analyzing untreated biological fluids such as plasma, serum, and urine. MLC is a better choice than ion-exchange LC or ion-pairing LC for separation of charged molecules and mixtures of charged and neutral species. Analysis of pharmaceuticals by MLC is also gaining popularity. Another novel application of MLC involves the separation and analysis of inorganic compounds, mostly simple ions. This is a relatively new area for MLC.

The aim of this work is to perform more accurate, reliable, fast and validated MLC method for determination of ITC in bulk, dosage form and spiked human plasma with a simple and rapid sample preparation especially for the routine analysis. Different chromatographic parameters were investigated to select the optimum conditions for the separation and for applying as stability-indicating method for determination ITC under different stress conditions. The result obtained by the proposed method was compared with that obtained by the HPLC technique [2]. The method was validated according to the international conference on harmonization guidelines (ICH) [25].

\section{Experimental}

\subsection{Materials}

ITC $(99.9 \%$ purity) was kindly supplied by Multiapex Pharma Drug Company (Egypt). The pharmaceutical products used were (1) Itrapex capsules (Apex pharma Co., Egypt), (2) Itracon capsules (Global Napi pharmaceuticals Co., Egypt), (3) Itranox capsules (Adwia Pharmaceutical Co., Egypt). All drugs contain $100 \mathrm{mg}$ ITC/capsule. They were obtained from local pharmacies.
Plasma samples were obtained from Egyptian Research and Development Company and kept frozen until using after gentle thawing.

\subsection{Reagents and chemicals}

All Reagents were of Analytical Reagent Grade and solvents were of HPLC grade. High purity water was obtained by Elga Labwater, Prima 7 (UK) and it was used throughout the study.

Methanol, 1-propanol and acetonitrile (HPLC grade) were obtained from Sigma-Aldrich (Germany). Ortho-phosphoric acid $(85 \%, w: v)$, triethylamine (TEA) and sodium dodecyl sulphate (SDS, 99\%) were obtained from Riedel-deHäen (Sleeze, Germany). Sodium Hydroxide, Hydrochloric acid (32\%, $w: v)$ were purchased from El-Nasr Company, Egypt. Hydrogen peroxide $(30 \%, w: v)$ was obtained from Luna industrial group ( $6^{\text {th }}$ of October City, Egypt).

\subsection{Instrumentations}

The MLC method was performed on a Gilson HPLC system equipped with a UV-VIS 156 detector and Gilson 321 pump. (Middleton, USA). Analytical data is stored in a computer equipped with Unipoint software and connected to the chromatographic system by a Gilson system interface. Vortex used was VWR VV3 S540 International West Charter-USA. Centrifuge used was centurion, (West Sussex-UK). The pH was measured with Jenway pH meter, 3510, (Essex-UK). The mobile phase was filtered through Charles Austen Pumps Ltd. filter, model-B100 SE (England, UK) using $0.45 \mu \mathrm{m}$ milli-pore filters (Gelman, Germany). UV-visible spectrophotometer used was Jasco, V-530, (Tokyo, Japan). Ultrasonic bath used was Falc, (Treviglio-Italy).

\subsection{Chromatographic conditions}

MLC was performed on a $\mu$ Bondapack Cyano column $(3.9 \times$ $150 \mathrm{~mm}, 5 \mu \mathrm{m}$ particle size), waters Corporation, Ireland using micellar mobile phase consisting of $0.1 \mathrm{M}$ sodium dodecyl sulphate (SDS), 20\% 1-propanol, 0.3\% triethylamine (TEA) in $0.02 \mathrm{M}$ ortho-phosphoric acid $(\mathrm{pH}=3.5)$. The mobile phase was filtered and sonicated for $30 \mathrm{~min}$ before use. The flow rate was $2.0 \mathrm{~mL} / \mathrm{min}$ and sample injection volumes were $20 \mu \mathrm{L}$ at room temperature $\left(25^{\circ} \mathrm{C}\right)$. The $\mathrm{UV}$ detector was operated at $258 \mathrm{~nm}$.

\subsection{Standard solutions}

Standard stock solution $(400 \mu \mathrm{g} / \mathrm{mL})$ of ITC was prepared by dissolving $10 \mathrm{mg}$ ITC in $25 \mathrm{~mL}$ methanol then the solution was sonicated in an ultrasonic bath for 5 minutes. The solutions were found to be stable for 3 days at room temperature. Working standard solutions $(120-320 \mu \mathrm{g} / \mathrm{mL})$ were prepared by appropriate dilutions of the standard stock solution with the mobile phase.

\subsection{Preparation of pharmaceutical products}

Take the contents of 20 capsules and determine the average weight of content per capsule. Accurate weight of the powder equivalent to $10 \mathrm{mg}$ ITC was dissolved in $25 \mathrm{~mL}$ methanol then sonication for $15 \mathrm{~min}$ and filtered.

\subsection{Plasma sample extraction}

$1 \mathrm{~mL}$ of human plasma was transferred into a centrifuge tube, spiked with $1 \mathrm{~mL}$ of ITC and deprotenized with $2 \mathrm{~mL}$ acetonitrile (ACN), then vortex. Final concentrations were 125, 150 and $175 \mu \mathrm{g} \mathrm{ITC} / \mathrm{mL}$, respectively. The solutions were centrifuged at $5000 \mathrm{rpm}$ for 15 minutes. Then, the solutions were filtered through a disposable syringe filter $(0.45 \mu \mathrm{m})$ before column injection. 
Table 1. Optimization of chromatographic conditions for the separation of ITC

\begin{tabular}{|c|c|c|c|c|c|c|}
\hline Parameter & Variation & $\begin{array}{l}\text { No of theoretical plates } \\
\text { (N) }\end{array}$ & $\begin{array}{l}\text { Capacity factor } \\
\left(\mathrm{K}^{\prime}\right)\end{array}$ & $\begin{array}{l}\text { Selectivity factor } \\
(\alpha)\end{array}$ & $\begin{array}{l}\text { Peak width } \\
(10 \%)\end{array}$ & $\begin{array}{l}\text { Tailing factor } \\
\left(t_{f}\right)\end{array}$ \\
\hline \multirow[t]{3}{*}{$\overline{\mathrm{pH}}$} & 2.5 & 640 & 2.15 & 6.26 & 0.59 & 1.46 \\
\hline & 3.5 & 505 & 1.43 & 4.77 & 0.38 & 1.23 \\
\hline & 4.5 & 465 & 1.39 & 4.73 & 0.36 & 1.25 \\
\hline \multirow[t]{2}{*}{ Conc. of SDS (M) } & 0.07 & 382 & 2.52 & 5.66 & 0.76 & 1.23 \\
\hline & 0.1 & 522 & 1.60 & 4.92 & 0.35 & 1.30 \\
\hline \multirow[t]{3}{*}{ Conc. of 1-propanol (\% v:v) } & 10 & 103 & 1.86 & 2.89 & 0.88 & 1.20 \\
\hline & 14 & 177 & 1.76 & 2.80 & 0.74 & 1.26 \\
\hline & 20 & 522 & 1.60 & 4.83 & 0.37 & 1.30 \\
\hline \multirow[t]{3}{*}{ Flow rate $(\mathrm{mL} / \mathrm{min})$} & 1.0 & 525 & 4.54 & 7.08 & 1.25 & 1.42 \\
\hline & 1.5 & 562 & 4.58 & 7.34 & 0.98 & 1.44 \\
\hline & 2.0 & 575 & 1.60 & 3.60 & 0.36 & 1.23 \\
\hline \multirow[t]{2}{*}{ Conc. of TEA $(\% v: v)$} & 0.2 & 96 & 1.69 & 2.75 & 0.70 & 1.30 \\
\hline & 0.3 & 505 & 1.60 & 3.60 & 0.36 & 1.20 \\
\hline
\end{tabular}

\subsection{Sample degradation}

An appropriate amount of ITC at a final concentration of $500 \mu \mathrm{g} / \mathrm{mL}$ in $1 \mathrm{~N}$ alcoholic $\mathrm{HCl}$ was left for 24 hours then the solution was filtered and $4 \mathrm{~mL}$ was taken into $10 \mathrm{~mL}$ volumetric flask and the volume was completed with the mobile phase, sonicated and triplicate $20 \mu \mathrm{L}$ injections were made. The same experiment was repeated but in $1 \mathrm{~N}$ alcoholic $\mathrm{NaOH}, 30 \% \mathrm{H}_{2} \mathrm{O}_{2}$ or the solutions of ITC were left in the sunlight for 24 hrs. Each experiment was carried out in triplicate and all solutions were injected in triplicate. The nominal contents of ITC were calculated using the constructed calibration graph or from the corresponding regression equation

\section{Results and discussion}

The proposed MLC method represents a rapid and sensitive stability-indicating assay method for the simultaneous determination of ITC in bulk and commercial capsules. By virtue of its high sensitivity, it was applied for the determination of ITC in human plasma with no need for tedious sample pre-treatment steps. Moreover, it was extended to investigate the inherent stability of ITC under different stressed conditions.

Different parameters affecting the chromatographic performance of ITC were carefully studied in order to achieve the most suitable chromatographic system. The results of the optimization study can be summarized as follows:

\subsection{Choice of appropriate detection wavelength}

ITC exhibits maximum absorption at 258 and $262 \mathrm{~nm}$ when measured in the mobile phase and in methanol, respectively. So, $258 \mathrm{~nm}$ was selected as it gives reasonable sensitivity. The absorption spectrum of ITC in the micellar mobile phase is shown in Figure 2.

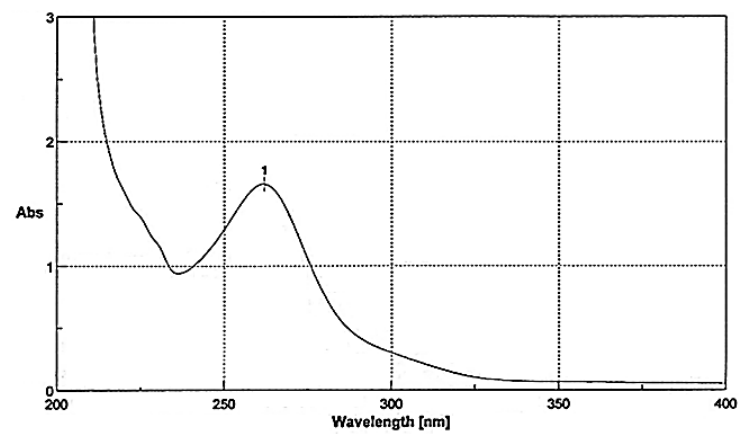

Figure 2. Absorption spectrum of ITC in the micellar mobile phase.

\subsection{Choice of column}

To investigate the chromatographic performance, different columns had been tried, these include reversed-phase $\mathrm{C}_{8}$, reversed-phase $\mathrm{C}_{18}$, bonded phase cyano and bonded phase phenyl columns. Experimental trials revealed that the $\mu$ Bondapack Cyano column $(3.9 \times 150 \mathrm{~mm}, 5 \mu \mathrm{m}$ particle size $)$ was the most suitable one giving narrower symmetric peaks and highest number of theoretical plates within a reasonable analysis time as shown in Figure 3 and Table 1.

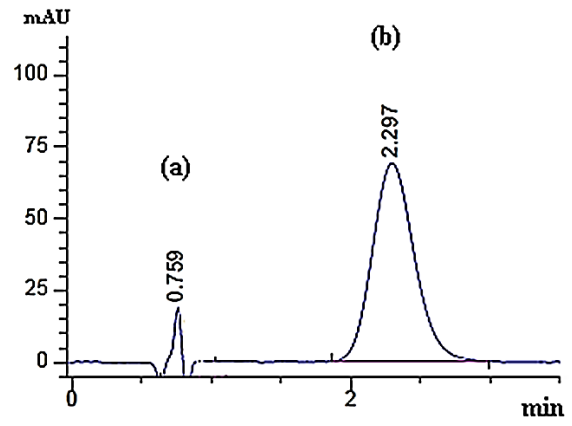

Figure 3. ITC Chromatogram under optimum chromatographic conditions using $\mu$ bondapack cyano column (a) Solvent front peak (b) ITC peak (200 $\mu \mathrm{g} / \mathrm{mL})$.

\subsection{Mobile phase composition}

To achieve the appropriate chromatographic conditions, the mobile phase composition was optimized to provide sufficient selectivity and sensitivity in a short separation time. The studied variables included; the $\mathrm{pH}$ of the mobile phase, flow rate, concentration of SDS, organic modifier and TEA. The results of such optimization study are presented in Table 1.

\subsection{1. pH of the mobile phase}

The effect of $\mathrm{pH}$ of the mobile phase was studied over the range of 2.5-4.5. Increasing the $\mathrm{pH}$ of the mobile phase more than 3.5 caused increase in the retention time of ITC. Therefore, $\mathrm{pH}=3.5$ was selected as the optimum $\mathrm{pH}$ value for the mobile phase yielding highest number of theoretical plates with good peak shape and lowest peak tailing.

\subsubsection{Concentration of SDS}

SDS concentration was varied over the range of 0.07-0.10 M. Mobile phase containing $0.07 \mathrm{M}$ SDS resulted in very broad peak. The retention time of the drug decreased as the molar concentration of SDS increased. 
Table 2. Accuracy of the proposed MLC method for the determination of ITC.

\begin{tabular}{|c|c|c|c|c|}
\hline \multirow[t]{2}{*}{ Parameter } & \multicolumn{3}{|l|}{ Proposed method } & \multirow{2}{*}{$\begin{array}{l}\text { Comparison method }[2] \\
\% \text { Found }{ }^{*}\end{array}$} \\
\hline & Conc. taken $(\mu \mathrm{g} / \mathrm{mL})$ & Conc. found $(\mu \mathrm{g} / \mathrm{mL})$ & \% Found * & \\
\hline & 120 & 121.6 & 101.3 & 100.9 \\
\hline & 160 & 157.2 & 98.3 & 99.1 \\
\hline & 200 & 200.9 & 100.5 & 102.0 \\
\hline & 240 & 240.3 & 100.1 & 100.2 \\
\hline & 320 & 319.9 & 100.0 & 99.2 \\
\hline $\mathrm{x} \pm \mathrm{SD}$ & & & $100.04 \pm 1.1$ & $100.3 \pm 1.2$ \\
\hline $\mathrm{t}$ & $0.3(1.9)^{* *}$ & & & \\
\hline $\mathrm{F}$ & $1.2(6.4)^{* *}$ & & & \\
\hline
\end{tabular}

** Values between parentheses are the tabulated $\mathrm{t}$ and $\mathrm{F}$ values at $n=15$ and $p=0.05$ [26].

The best compromise in terms of run time, efficiency and peak symmetry was achieved upon using a mobile phase containing $0.10 \mathrm{M}$ SDS.

\subsubsection{Concentration of organic modifier}

Concentration of 1-propanol was varied over the range of $10-20 \%$. As expected, the retention of ITC decreases as percentage of organic modifier increases. In addition, peak broadening was observed at low concentrations of 1-propanol. A concentration of $20 \%$ of 1 -propanol was chosen as the optimal concentration, where it offers a good combination of peak symmetry and analysis time. Zero concentration of propanol was tried and no peak appears till $20 \mathrm{~min}$.

\subsubsection{Concentration of triethyl amine (TEA)}

TEA is added to the mobile phase to bind the silanol groups. This reduces the tailing of basic compounds which is not due to the micellar phase. To study the influence of the concentration of TEA on the peak of ITC, it was varied over the range of 0.2$0.3 \%$. It was found that the peak tailing, peak asymmetry and number of theoretical plates are better with $0.3 \%$ TEA. The recorded performance parameters were listed in Table 1.

\subsubsection{Flow rate of the mobile phase}

The effect of flow rate of the mobile phase on the retention of ITC was investigated over the range of $1.0-2.0 \mathrm{~mL} / \mathrm{min}$. Flow rate of $2.0 \mathrm{~mL} / \mathrm{min}$ was chosen since it provides better peak shape within a reasonable time.

After optimization of these variables, best peak shape and lowest peak tailing were achieved with well-defined peaks and good sensitivity within a reasonable analytical run time. Figure 3 represents a chromatogram indicating the good retention of ITC under the optimum chromatographic conditions.

\subsection{Method validation}

The validity of the proposed method was assessed by studying the following parameters in accordance to ICH guideline [25]: linearity, LOD, LOQ, accuracy, precision, selectivity, sample solution stability, mobile phase stability, system suitability and robustness.

\subsubsection{Linearity}

Under the optimum chromatographic conditions, a linear relationship was established over the concentration ranges of 16.4-320.0 $\mu \mathrm{g} / \mathrm{mL}$ ITC (Figure 4) with good correlation coefficient $(r)$ and relative standard deviation (R.S.D.) (1.05\%) according to the following regression equation:

$$
\mathrm{y}=15545 \mathrm{x}-40170(r=0.9997)
$$

Limit of detection (LOD) (The lowest concentration that can be determined) and Limit of quantification (LOQ) (The lowest concentration of a substance that can be quantified with acceptable precision and accuracy) for ITC were calculated according to ICH Q2 (R1) recommendation [25]. LOD and LOQ were found 5.4 and $16.4 \mu \mathrm{g} / \mathrm{mL}$, respectively.

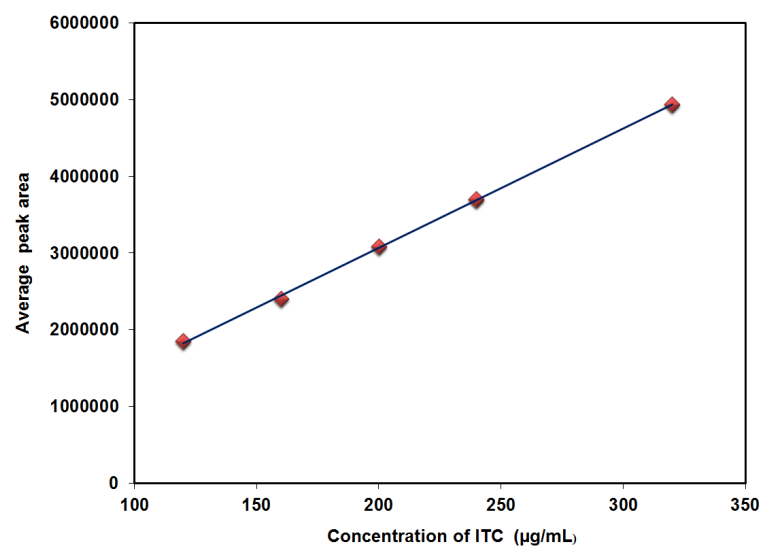

Figure 4. Calibration curve for MLC determination of ITC

\subsubsection{Accuracy}

To prove the accuracy of the proposed method, the results of the assay of ITC in pure form by the proposed MLC method were compared with those obtained using a reference HPLC method [2]. Statistical comparison using $t$-test and $F$-test revealed no significant differences between the performance of the two methods regarding the accuracy and precision, respectively as illustrated in Table 2 .

\subsubsection{Precision}

Intra-day precision was achieved by six replicate determination of $200 \mu \mathrm{g} / \mathrm{mL}$ in the three dosage forms on three successive times in the same day. Inter-day precision was performed as intra-day precision but on three successive days. Small values of \%error and \%RSD revealed the precision of the proposed method. The results are illustrated in Table 3.

\subsubsection{Selectivity}

The Selectivity of the proposed MLC method was established by its ability to determine ITC in commercial capsules without interference from common tablet additives. The common capsule additives did not show any interfering peaks at the retention times of the drug, which proved the homogeneity and purity of the peak. Furthermore, to evaluate the specificity of the method to determine ITC in human plasma, blank plasma was diluted with the micellar mobile phase and injected under the recommended chromatographic conditions. No endogenous interference was observed at the retention time of ITC, proving the specificity of the method. 
Table 3. Precision data of the proposed method for the determination of ITC in dosage forms.

\begin{tabular}{llll} 
Tarameters & \% Found \pm SD & \%RSD & \%Error \\
\hline Intra-day precision & $102.8 \pm 1.4$ & 1.36 & 0.3 \\
Itrapex cap & $99.2 \pm 1.2$ & 1.21 & 0.3 \\
Itracon cap & $103.5 \pm 0.5$ & 0.51 & 0.1 \\
Itranox cap & & & \\
\hline Inter-day precision & $103.4 \pm 1.2$ & 1.16 & 0.3 \\
Itrapex cap & $98.2 \pm 1.2$ & 1.22 & 0.3 \\
Itracon cap & $102.2 \pm 0.8$ & 0.78 & 0.2 \\
Itranox cap & & \\
\hline
\end{tabular}

Table 4. SST parameters for the developed $200 \mu \mathrm{g} / \mathrm{mL}$ MLC method.

\section{Parameters}

No of theoretical plates, $\mathrm{N}$

Capacity factor, $\mathrm{K}^{\prime}$

Selectivity factor, $\alpha$

Resolution factor, $R_{\mathrm{s}}$

Forced degradation studies were also performed to evaluate the validity of the method. The results obtained indicated that the proposed MLC method is selective and able to determine ITC in presence of its degradation products.

\subsubsection{Sample solution stability and mobile phase stability}

Evaluation of the stability of ITC solution was achieved by quantification of ITC on three successive days and comparison to freshly prepared solution. Similarly, the stability of the mobile phase was checked. No significant changes were observed in standard solution or mobile phase responses, proved that they were stable up to 3 days.

\subsubsection{System suitability test (SST)}

Evaluation of SST parameters was performed during the development and optimization of the method. Moreover, to ascertain the effectiveness of the final operating system, it was subjected to suitability testing. The test was performed by injecting the standard sample in triplicate and the SST parameters were calculated as reported by USP [27] which include capacity factor $\left(\mathrm{k}^{\prime}\right)$, selectivity factor $(\alpha)$, Resolution factor $\left(R_{\mathrm{s}}\right)$, column efficiency (number of theoretical plates, $\mathrm{N}$ ). The final SST parameters under the optimum chromatographic conditions are summarized in Table 4.

\subsubsection{Robustness}

To assess the robustness of the proposed MLC method, the chromatographic conditions were deliberately altered such as concentration of 1-propanol $(20 \pm 0.5 \%, v: v)$, strength of orthophosphoric acid $(0.02 \pm 0.005 \mathrm{M})$, concentration of TEA $(0.3 \pm 0.01 \%)$. The efficiency of the separation of ITC was not affected indicating the reliability of the proposed method. Therefore, the method is robust to the small changes in experimental conditions.

\subsection{Applications}

\subsubsection{Application of the proposed method to the determination of ITC in capsules}

The developed MLC method was applied successfully for the assay of ITC in commercial capsules as shown in Figure 5. The results obtained by the developed MLC method were statistically compared with those of the reference HPLC method [2] using the $t$-test and $F$-test. The results show that there were no significant differences between the developed and reference methods regarding accuracy and precision, respectively as illustrated in Table 5.

The proposed method showed satisfactory results for determination of ITC in spiked human plasma. The assay results using the proposed method are summarized in Table 6 .

\subsubsection{Application of the proposed method to the determination of ITC in spiked human plasma}

MLC allows biological samples to be analyzed without prior tedious pre-treatment for plasma protein precipitation or elimination of other interfering substances, thus considerably reducing the cost and analysis time. The proposed MLC method was successfully applied to the determination of ITC in spiked human plasma.
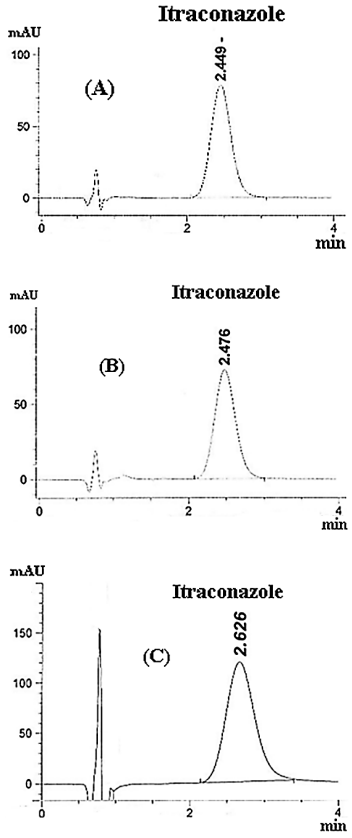

Figure 5. Representative chromatogram showing $200 \mu \mathrm{g} / \mathrm{mL}$ ITC in different capsule formulations, where: (A) Itracon capsule (B) Itrapex capsule (C) Itranox capsule.

Table 5. Application of the proposed and reference method for the determination of ITC in capsules.

\begin{tabular}{lll}
\hline $\begin{array}{l}\text { Pharmaceutical } \\
\text { preparation }\end{array}$ & \multicolumn{2}{l}{ \% Found ${ }^{*}$ mean \pm SD } \\
\cline { 2 - 3 }$t^{* *}$ & Proposed & Reference [2] \\
\hline Itrapex cap & $99.3 \pm 1.2$ & $99.6 \pm 1.5$ \\
$\mathrm{~F}^{* *}$ & 0.3 & - \\
\hline Itranox cap & 1.7 & - \\
$t^{* *}$ & $105.1 \pm 0.5$ & $104.4 \pm 0.8$ \\
$\mathrm{~F}^{* *}$ & 0.3 & - \\
\hline Itracon cap & 2.3 & - \\
$t^{* *}$ & $106.4 \pm 0.6$ & $106.6 \pm 0.6$ \\
$\mathrm{~F}^{* *}$ & 0.4 & - \\
\hline * Each result is the average of five separate determinations and each one \\
repeated three times. \\
** The tabulated $t=1.9$ and $F=6.4$ at $n=15$ and $p=0.05[26]$.
\end{tabular}


Table 6. Assay Results for the determination of ITC in spiked human plasma using the proposed method.

\begin{tabular}{llll}
\hline Parameter & $\begin{array}{l}\text { Conc. added } \\
(\boldsymbol{\mu g} / \mathbf{m L})\end{array}$ & $\begin{array}{l}\text { Conc. found } \\
(\boldsymbol{\mu g} / \mathbf{m L})\end{array}$ & \% Recovery * \\
\hline Spiked plasma & 125 & 125.4 & 100.3 \\
& 150 & 145.6 & 97.1 \\
& 175 & 166.2 & 94.9 \\
\hline Mean \% \pm SD & $97.5 \pm 2.7$ & & \\
\% R.S.D & 2.8 & & \\
\% Error & 0.9 & & \\
\hline
\end{tabular}

* Each result is the average of three separate determinations.

\subsubsection{Results of stress testing studies}

Stability testing of ITC was performed under various stress conditions in order to assure the selectivity and provide an indication of the stability-indicating properties of the proposed MLC method.

The studied compound is found to be highly labile to alkaline hydrolysis which resulted in about 85 and $82 \%$ degradation of ITC in itrapex and itracon capsule, respectively, while the peak of ITC in itranox capsule was nearly diminished as illustrated in Figure 6. Where the acidic degradation using 1 $\mathrm{N} \mathrm{HCl}$ for $24 \mathrm{hrs}$ showed that about $10 \%$ degradation in the three dosage forms as illustrated in Figure 7. Exposure of ITC capsules to oxidative degradation by $30 \% \mathrm{H}_{2} \mathrm{O}_{2}$ for $24 \mathrm{hrs}$, about 69, 63 and $65 \%$ degradation of ITC in itrapex cap., itranox cap. and iracon cap., respectively, as illustrated in Figure 8. ITC did not exhibit any degradation peaks that could interfere with the proposed MLC method. No degradation was seen under photolytic conditions.
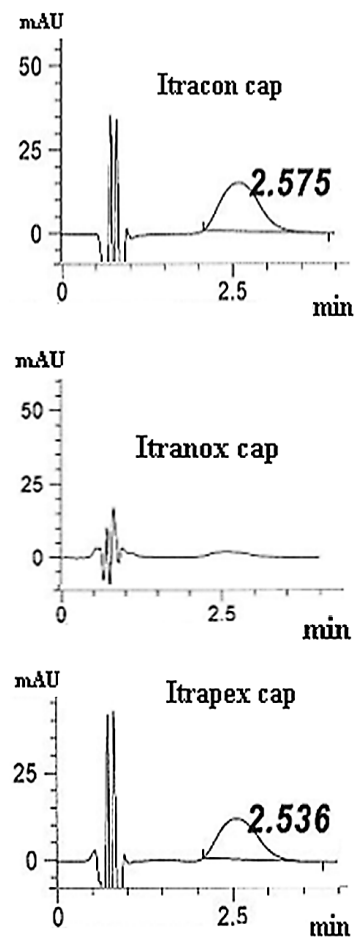

Figure 6. Alkaline degradation of $200 \mu \mathrm{g} / \mathrm{mL}$ ITC in its three dosage forms.

\section{Conclusion}

The proposed MLC method represents a new rapid and sensitive stability-indicating assay for the determination of ITC in bulk and commercial capsules. The proposed method was applied successfully for the determination of ITC in human plasma with no need for tedious sample pre-treatment steps. In addition, the proposed method was extended to investigate the inherent stability of ITC under different stress conditions.
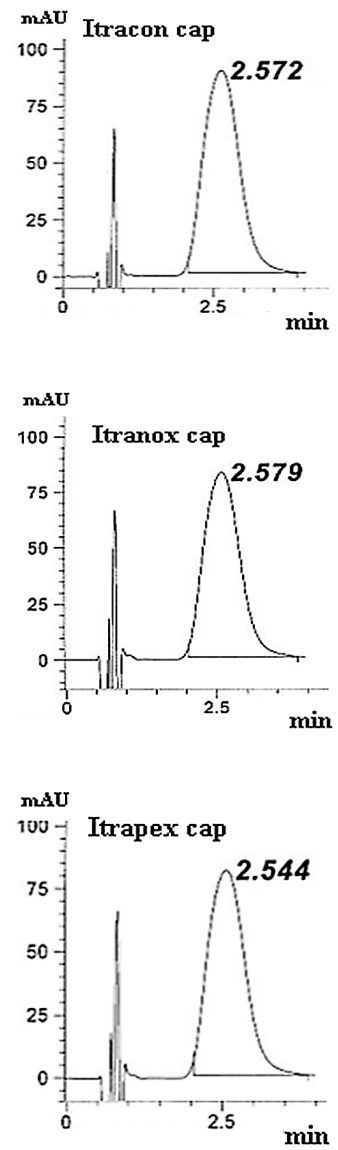

Figure 7. Acidic degradation of $200 \mu \mathrm{g} / \mathrm{mL}$ ITC in its three dosage forms.
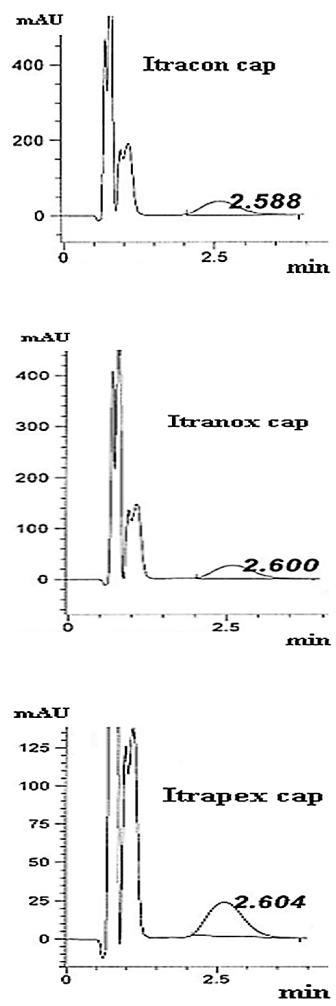

Figure 8. Oxidative degradation of $200 \mu \mathrm{g} / \mathrm{mL}$ ITC in its three dosage forms. 


\section{Acknowledgements}

The authors thank Egyptian Research and Development Company for kindly effort providing during this work.

\section{References}

[1]. Ghannoum, M. A.; Rice, L. B. Clin. Microbiol. Rev. 1999, 12, 501-517.

[2]. British Pharmacopoeia, British Pharmacopoeia Commission, The Stationery Office, London, UK, 2012.

[3]. European Pharmacopoeia, 5th ed. Supplements 1-5. Strasbourg, Council of Europe, 2005-2006.

[4]. Miura, M.; Takahashi, N.; Nara, M.; Fujishima, N.; Kagaya, H.; Kameoka, Y. Ann. Clin. Biochem. 2010, 47, 432-439.

[5]. Gagliardi, L.; De-Orsi, D.; Chimenti, P.; Porra, R.; Tonelli, D. Anal. Sci. 2003, 19, 1195-1197.

[6]. Ohkubo, T.; Osanai, T. Ann. Clin. Biochem. 2005, 42, 94-98.

[7]. Khoschsorur, G.; Fruehwirth, F.; Zelzer, S. Antimicrob. Agents Chemother. 2005, 49, 3569-3571.

[8]. Yoo, S. D.; Lee, S. H.; Kang, E.; Jun, H.; Jung, J. Y.; Park, J. W.; Lee, K. H. Drug Dev. Ind. Pharm. 2000, 26, 27-34.

[9]. AlRawithi, S.; Hussein, R.; Al-Moshen, I.; Raines, D. Ther. Drug Monit. 2001, 23, 445-448.

[10]. Gordien, J.; Pigneux, A.; Vigouroux, S.; Tabrizi, R.; Accoceberry, I. J. Pharm. Biomed. Anal. 2009, 50, 932-938.

[11]. Jaruratanasirikul, S.; Sriwiriyajan, S. Eur. J. Clin. Pharmacol. 2007, 63, 451-456.

[12]. Kumar, V.; Wang, L.; Riebe, M.; Tung, H.; Prud-homme, R. Mol. Pharm. 2009, 6, 1118-1124.

[13]. Bharathi, V.; Hotha, K.; Sagar, P. V.; Kumar, S. S.; Reddy, P. R.; Naidu , A.; Mullangi, R. J. Chromatogr. B 2008, 868, 70-76.

[14]. Wook Choi, Y.; Nam, D.; Kang, K. H.; Wook Ha, K.; Han, I. H.; Chang, B. K.; Yoon, M.; Lee, J. Bull. Korean Chem. Soc. 2006, 27, 291-294.

[15]. Rhim, S. Y.; Park, J. H.; Park, Y. S.; Kim, D. S.; Lee, M. H; Shaw, L. M; Kang, J. S. Pharmazie 2009, 64, 71-75.

[16]. Yao, M.; Chen, L. S.; Srinivas, N. R. J. Chromatogr. B 2001, 752, 9-16.

[17]. Castro-Puyana, M.; Crego, A. L.; Marina, M. L. Electrophoresis 2006, 27, 887-895.

[18]. Breadmore, M.; Prochazkova, A.; Theurillat, R.; Thormann, W. J. Chromatogr. A 2003, 1014, 570-578.

[19]. Zhang, C. X.; Von-Heeren, F.; Thormann, W. Anal. Chem. 1995, 67, 2070-2077.

[20]. Crego, A. L.; Gomez, J.; Marina, M. L.; Lavandera, J. L. Electrophoresis 2001, 22, 2503-2511.

[21]. Radoslaw, J. E.; Krzek, J. Acta Pol. Pharm. 2009, 66, 19-23.

[22]. El-Enany, N.; El-Sherbiny, D.; Belal, F. J. Chin. Chem. Soc. 2007, 54, 375382.

[23]. Armstrong, D.; Henry, S. J. Liq. Chromatogr. R. T. 1980, 3, 657-662.

[24]. Berthod, A. J. Chromatogr. A 1997, 780, 191-206.

[25]. Validation of analytical procedure: Text and Methodology. International Conference on Harmonization Q2(R1), 2005. Accessed at:

http://www.bioforum.org.il/Uploads/Editor/karen/q2 r1 step4.pdf

[26]. Miller, J. C.; Miller, J. N. Statistics and Chemometrics for Analytical Chemistry, $5^{\text {th }}$ edition. Pearson Education Limited: Harlow, England, 2005, pp. 39-73, 107-149, 256.

[27]. The United States Pharmacopeia, 30 $30^{\text {th }}$ rev., and the National Formulary $25^{\text {th }}$ ed. Rockville, MD: The United States Pharmacopeial Convention, 2007. 